\title{
Improvement of surface photostability of bamboo scrimber by application of organic UV absorber coatings
}

\author{
Neng Li ${ }^{1,2,3}$, Minzhen Bao ${ }^{1,3}$, Fei Rao ${ }^{1,2}$, Yi Shu' ${ }^{1}$, Chengjian Huang ${ }^{1,3}, Z_{\text {Zhonghua Huang }}^{4}$, Yuhe Chen ${ }^{1,3 *}$, \\ Yongjie Bao ${ }^{1,2^{*}}$, Rencong Guo ${ }^{1}$ and Chengming Xiu ${ }^{1}$
}

\begin{abstract}
Improving the durability of biological materials is essential for expanding their application areas. In this study, an organic ultraviolet (UV) shielding layer (coating) composed of a UV-curable paint, ethyl acetate, anhydrous alcohol, and an organic UV absorber is constructed on the surface of outdoor bamboo scrimber (OBS). The behaviour of OBS with or without this coating was investigated under accelerated weathering. The physical properties photostability of the samples before and during exposure were evaluated by characterizing the colour and glossiness. Contact angle (CA) measurements and surface free energy (SFE) calculations were performed to investigate the wettability of the coatings. Attenuated total reflectance Fourier transform infrared spectroscopy was used to characterize the changes in the functional groups of the coatings during weathering. The experimental results have shown that the colour, glossiness, CA, SFE, and functional groups photostability of the sample with the UV shielding coating increased significantly compared to those of the control sample. The coating with 5\% organic UV absorber was considered as the best UV shielding layer in this study, as it successfully protected the OBS and reduced the surface photodegradation of the substrate and the coating itself.
\end{abstract}

Keywords: Outdoor bamboo scrimber, Photodegradation, Organic UV absorber

\section{Introduction}

The favourable properties of bamboo scrimber products in terms of dimensional stability, natural colour, elegant texture, and ease of processing has led to its widespread application. Further, bamboo scrimber is considered to be a good biological material for outdoor application [1]. However, when it is exposed to outdoor conditions, such as solar radiation, moisture, oxygen, high temperature, and bacteria and fungi, its exterior tends to undergo discolouration, decreasing the glossiness and increasing the roughness. Further, it loses its strength and adhesiveness and becomes sensitive to decay [2-6]. Among the abovementioned factors, solar radiation, especially ultraviolet (UV) radiation, is the major contributor of degradation.

\footnotetext{
*Correspondence: yuhec@sina.com; baoyongjie1@126.com

${ }^{1}$ China National Bamboo Research Center, Hangzhou 310012, People's

Republic of China

Full list of author information is available at the end of the article
}

Therefore, the investigation of how to reduce the effect of UV radiation on bamboo scrimber and other biological materials is essential to improve the durability of bamboo products.

Under the combined action of water and oxygen, the high energy of UV radiation initiates various chemical reactions on the surfaces of exposed natural and synthetic organic substrates. The most effective technique for protection against UV radiation is to cover the exposed surfaces with coatings containing inorganic and organic UV radiation absorbers [7]. Extensive research has focused on the application of inorganic absorbers, such as $\mathrm{ZnO}$ and $\mathrm{TiO}_{2}$ nanoparticles, to UV radiation shielding coatings $[3,8]$. Due to the fact that they are inorganic and particulate, which endowed them with stable and nonmigratory [9]. Meanwhile, $\mathrm{ZnO}$ and $\mathrm{TiO}_{2}$ nanoparticles have both been used in coatings to bestow antimicrobial properties and improve the thermal stability [10] and refractive indices of transparent polymers [3]. 
However, these advantages require the particles to be of nanosize, which is difficult to achieve homogeneously disperse nanoparticles in a coating [11]. Surface modification is a common method to improve the dispersion of nanoparticles in the coating. This method also may result in detrimental for UV radiation shielding capability of coatings [12]. Some studies have found that $\mathrm{ZnO}$ and $\mathrm{TiO}_{2}$ nanoparticles are opaque to partial visible light, especially over wavelengths of 400-500 nm. Therefore, they may not be the most suitable materials to form clear UV radiation shielding coatings $[9,13]$. Organic UV absorbers, such as benzotriazoles, triazines, malonates, and oxalanilides, also have the ability to absorb UV radiation [5, 14, 15]. Organic UV absorbers exhibit high UV-radiation absorption rates and good transmission in visible light [5]. Comparative studies on the photostabilities of coatings to which benzotriazoles and micronized $\mathrm{TiO}_{2}$ have been added have found that benzotriazoles are better than $\mathrm{TiO}_{2}[16,17]$.

The objective of this study was to determine the effect of the addition of organic UV absorbers on the surface photostabilities of coatings and bamboo scrimber. A UV shielding coating composed of 2-(2-hydroxy-3-tert-butyl5-methyl-phenyl)-5-chlorinated benzotriazole (BTZ-1), a UV-curable paint, ethyl acetate, and anhydrous alcohol was applied on outdoor bamboo scrimber (OBS). The durability of OBS with or without the coating was investigated by examining the photostability of surface properties during artificial weathering. Physical changes occurring in the coatings and substrate before and during exposure were investigated in terms of the colour and glossiness. The wettability of the samples before and after accelerated weathering was evaluated through contact angle (CA) measurements and surface free energy (SFE) calculations. Changes in the functional groups of the coatings were determined using attenuated total reflectance Fourier transform infrared spectroscopy (ATR FT-IR).

\section{Materials and methods}

\section{Formulations of organic UV absorber coatings}

A UV-curable paint, ethyl acetate, anhydrous alcohol, and BTZ-1 were used to prepare organic UV absorber coatings (Table 1). The UV-curable paint, which was used as a binder, was bought from Jiangsu Himonia Technology Co., Ltd, China. BTZ-1 was also obtained commercially (Taiyuan Saisili Fine Chemical Co., Ltd, China). The UV-curable paint, ethyl acetate, and anhydrous alcohol were initially mixed with a stirrer at $1000 \mathrm{rpm}$ for $30 \mathrm{~min}$. Then, BTZ-1 was added into the clear coat resin. The coatings were prepared at high speed (2000 rpm) using a stirrer. The content of each component is shown
Table 1 Coating formulations

\begin{tabular}{lllll}
\hline $\begin{array}{l}\text { Coatings } \\
\text { formulation }\end{array}$ & $\begin{array}{l}\text { BTZ-1 } \\
\text { concentration } \\
\text { (\%) }\end{array}$ & $\begin{array}{l}\text { UV-curable } \\
\text { painting (\%) }\end{array}$ & $\begin{array}{l}\text { Ethyl } \\
\text { acetate } \\
\text { (\%) }\end{array}$ & $\begin{array}{l}\text { Anhydrous } \\
\text { alcohol (\%) }\end{array}$ \\
\hline b & 0.0 & 97.5 & 1 & 1.5 \\
c & 2.5 & 95.0 & 1 & 1.5 \\
d & 5.0 & 92.5 & 1 & 1.5 \\
\hline
\end{tabular}

in Table 1. The coating b, which consisted of $0 \% \mathrm{UV}$ absorber (BTZ-1), was considered as the control.

\section{Sample preparation}

The substrate OBS was prepared according to the standard procedure [1]. Four-year-old moso bamboo (Phyllostachys pubescens Mazel) culms were harvested at a plantation located in Anhui Province in eastern China. Each culm of 5-6 mm in thickness was split longitudinally into two semi-circular parts, and the edges were trimmed into 450-mm-long pieces. Net-like oriented bamboo-fibre mats (OBFMs) were formed by fluffing and flattening the fibres along their longitudinal axis. The mats were then oven-dried to ensure a moisture content of $6-8 \%(\mathrm{w} / \mathrm{w})$. The OBFMs were then heat treated at $200{ }^{\circ} \mathrm{C}$ for $2 \mathrm{~h}$ under vapor protection. The carbonized OBFMs were soaked in a $20 \%(\mathrm{w} / \mathrm{w})$ phenol formaldehyde (PF) resin (Beijing Taier Chemical Co., Ltd., Beijing, China) solution for approximately $5 \mathrm{~min}$ to achieve a resin content of $14 \%(\mathrm{w} / \mathrm{w})$. After immersion in $\mathrm{PF}$, the OBFMs were oven-dried at $55^{\circ} \mathrm{C}$ until they had a moisture content of $11-12 \%$. All of the weighed mats were assembled symmetrically along the grain, with the outer layer being outward and the inner surface being inward, such that they could be laid evenly and loosely to form slabs. The slabs were transferred to a single-opening hydraulic hot press (QD, Shanghai Artificial Board Machinery Factory Co., Ltd., China) for hot pressing at a hot-plate temperature of $145{ }^{\circ} \mathrm{C}$ for a holding time of $1 \mathrm{~min} \mathrm{~mm}^{-1}$. This resulted in a slab thickness of $20 \mathrm{~mm}$. Finally, OBS with a target density of $1.1 \mathrm{~g} \mathrm{~cm}^{-3}$ was obtained by cutting the edges of the samples.

Prior to application of the paint, the OBS was sanded in a heavy sanding machine (HSM) (TMZ-400, Chengdu Senlian Woodworking Machinery Co., Ltd., China) to achieve a uniform thickness. Then, three types of paints were sequentially applied on the surface of the OBS. First, a base coat (Jiangsu Himonia Technology Co., Ltd, China) was applied 2 times on the OBS surface by a roller coating machine, and solidification was conducted using $\mathrm{UV}$ radiation; the paint amount was $15-25 \mathrm{~g} \mathrm{~m}^{-2}$ per time. Next, two layers of sanding primer (Jiangsu Himonia Technology Co., Ltd, China) were applied on the OBS, 
with the applied quantity being $15-30 \mathrm{~g} \mathrm{~m}^{-2}$ per time, and the samples were then cured under UV radiation and sanded in an HSM. Finally, the above-prepared organic UV absorber coating as a finishing coat was applied 2 times on the outermost layer of the OBS to form a UV protective coating. In addition, they were cured using a UV curing machine, and the average coating weight of the finishing coat of all samples was $36.87 \mathrm{~g} \mathrm{~m}^{-2}$, which was calculated according to the critical BTZ-1 loading amount for complete UV radiation protection [5]. Samples $\mathrm{B}-\mathrm{D}$, treated with finishing coats $\mathrm{b}-\mathrm{d}$, respectively, were prepared (Table 2); sample A without any paint was considered as the blank control, and sample B treated with coating b, which did not contain BTZ-1, was also regarded to be a control. Depending on the testing and analysis requirements, samples of different dimensions were cut and marked.

\section{Accelerated weathering}

The accelerated weathering tests were performed in a UV weathering test box (Hangzhou Nine Rings Fu Da Industrial Co., Ltd, China) according to ASTM G154-12a [18]. The samples were cyclically exposed to UV-A radiation $(\lambda=313 \mathrm{~nm})$ at a black panel temperature of $60^{\circ} \mathrm{C}$ for $4 \mathrm{~h}$ and were subjected to condensation treatment without UV radiation at a black panel temperature of $50{ }^{\circ} \mathrm{C}$ for $4 \mathrm{~h}$. The intensity of UV irradiation was $0.71 \mathrm{~W} \mathrm{~m}^{-2}$ at $313 \mathrm{~nm}$.

\section{Color measurement}

Six measurements at precisely defined points on the sample surfaces were performed using a colorimeter (CM3600 d, Konica Minolta Investment Ltd, Japan). Chromatic coordinates, $L^{*}, a^{*}$, and $b^{*}$," of the CIELAB colour system were measured according to ASTM E1347 [19]. Colour differences $\Delta E$ were calculated according to Eq. (1):

$$
\Delta E=\sqrt{\left(L_{1}^{*}-L_{0}^{*}\right)^{2}+\left(a_{1}^{*}-a_{0}^{*}\right)^{2}+\left(b_{1}^{*}-b_{0}^{*}\right)^{2}}
$$

where $L_{0}^{*} a_{0}^{*}$ and $b_{0}^{*}$ and $L_{1}^{*}, a_{1}^{*}$, and $b_{1}^{*}$ are the chromatic coordinates of the samples before and after accelerated weathering, respectively.

Table 2 Samples formulation

\begin{tabular}{llll}
\hline Samples & Substrate & $\begin{array}{l}\text { Treatment of base coat } \\
\text { and sanding primer paint } \\
\text { or not }\end{array}$ & $\begin{array}{l}\text { Finishing } \\
\text { coat }\end{array}$ \\
\hline A & OBS & - & - \\
B & OBS & Yes & b \\
C & OBS & Yes & C \\
D & OBS & Yes & d
\end{tabular}

OBS outdoor bamboo scrimber, the formulation of finishing coat $b-d$ were shown

\section{Gloss analysis}

Surface specular glossiness of the samples was measured at an angle of incidence of $60^{\circ}$ using a portable universal gloss meter (Bonsai Instrument Technology (Shanghai) Co., Ltd., China) according to ASTM D523 standard [20]. The results were based on a specular gloss value of 100 , which corresponded to illumination and viewing conditions identical to a highly polished, plain black glass surface. The difference in the glossiness values was represented as the percentage glossiness change $(\Delta G \%)$, which was calculated using the following formula:

$$
\Delta G \%=\frac{\left(G_{t}-G_{o}\right)}{G_{o}} \times 100 \%
$$

where the subscripts $o$ and $t$ denote the values before and after the exposure, respectively, of the specimen in question, exposed to the weathering conditions for $t \mathrm{~h}$. Four replicate measurements were performed for each sample surface.

\section{CA measurements}

Parts of samples with dimensions of $25 \times 25 \times 18 \mathrm{~mm}$ were specially prepared for CA measurements. The CAs of the samples were determined by the sessile drop technique using a CA analyser (DSA 100, Kruss, Germany). Water, formamide, and diiodomethane were the test liquids. Data collection began as soon as the test droplets were detected to have touched the material surface; this typically occurred within $0-3$ frames ( 1 frame $\approx 19.2 \mathrm{~ms}$ ). All CA data were collected within $8 \mathrm{~s}$ from the starting point of measurement.

\section{Calculation of SFE}

The SFE components of the test liquids according to Fombuena et al. [21] and $\mathrm{Li}$ et al. [22] are presented in Table 3. The SFEs of the samples were calculated according to the Lifshitz-van der Waals acid-base approach [23]. As Bryne and Wålinder [24] suggested, the SFEs of the samples could be calculated from the initial CAs of water (polar), formamide (polar), and diiodomethane (nonpolar) according to Eqs. (3), (4), and (5):

$$
\begin{aligned}
& \gamma_{\mathrm{S}}=\gamma_{\mathrm{S}}^{\mathrm{LW}}+\gamma_{\mathrm{S}}^{\mathrm{AB}} \\
& \gamma_{\mathrm{S}}^{\mathrm{AB}}=2 \sqrt{\gamma_{\mathrm{S}}^{+} \gamma_{\mathrm{S}}^{-}} \\
& (1+\cos \theta) \gamma_{L}=2\left(\sqrt{\gamma_{\mathrm{S}}^{\mathrm{LW}} \gamma_{\mathrm{L}}^{\mathrm{LW}}}+\sqrt{\gamma_{\mathrm{S}}^{+} \gamma_{\mathrm{L}}^{-}}+\sqrt{\gamma_{\mathrm{S}}^{-} \gamma_{\mathrm{L}}^{+}}\right)
\end{aligned}
$$

where $\gamma_{S}$ is the surface free energy of samples $\left(\mathrm{mJ} \mathrm{m}^{-2}\right)$, $\gamma_{\mathrm{S}}^{\mathrm{LW}}$ is the apolar (Lifshitz-van der Waals) component of surface free energy of samples $\left(\mathrm{mJ} \mathrm{m}^{-2}\right), \gamma_{\mathrm{S}}^{\mathrm{AB}}$ is the polar 
Table 3 Information about three reference liquids

\begin{tabular}{|c|c|c|c|}
\hline Reference liquids & Molecular formula & Molecular mass & Supplier \\
\hline Deionized water & $\mathrm{H}_{2} \mathrm{O}$ & 18.01 & $\begin{array}{l}\text { Treated by SMART Series SNW Ultra-pure Water } \\
\text { System } \\
\text { (Heal Force Bio-Meditech Holdings Limited, Heal } \\
\text { Force, Shanghai, China) }\end{array}$ \\
\hline Formamide & $\mathrm{HCONH}_{2}$ & 45.04 & Chengdu Kelong Chemical Reagent Co., Ltd., China \\
\hline Diiodomethane & $\mathrm{CH}_{2} \mathrm{I}_{2}$ & 267.84 & Aladdin Industrial Corporation, China \\
\hline
\end{tabular}

(Lewis acid-base) component of surface free energy of samples $\left(\mathrm{mJ} \mathrm{m}{ }^{-2}\right), \gamma_{\mathrm{S}}^{+}$is the electron-accepting component of acid-base components of samples $\left(\mathrm{mJ} \mathrm{m}^{-2}\right), \gamma_{\mathrm{S}}^{-}$ is the electron-donating component of acid-base components of samples $\left(\mathrm{mJ} \mathrm{m}^{-2}\right), \theta$ is the liquid CA on samples $\left(^{\circ}\right), \gamma_{\mathrm{L}}^{\mathrm{LW}}$ is the apolar component of liquid surface free energy $\left(\mathrm{mJ} \mathrm{m}^{-2}\right), \gamma_{\mathrm{S}}^{+}$is the electron-accepting component of liquid acid-base components $\left(\mathrm{mJ} \mathrm{m}^{-2}\right)$, and $\gamma_{\mathrm{S}}^{-}$is the electron-donating component of liquid acid-base components $\left(\mathrm{mJ} \mathrm{m} \mathrm{m}^{-2}\right)$.

\section{FT-IR analysis}

ATR FT-IR spectra of the coatings of sample B and D were recorded using a Nicolet iS10 spectrophotometer (Thermo Scientific, USA) equipped with a diamond crystal attenuated total reflection accessory (Smart iTX, Thermo Scientific, USA). The resolution was set at $4 \mathrm{~cm}^{-1}$, and 64 scans were recorded for each analysis with a scanning range of $400-4000 \mathrm{~cm}^{-1}$.

\section{Results and discussions \\ Colour changes}

The colour changes are related to chemical changes such as the degradation of OBS lignin and coatings, which degrades the aesthetics of the material surface [1]. The colour changes in response to the UV irradiation of the surfaces of the samples with the different treatments are shown in Fig. 1. The average values of original $L^{*}, a^{*}$ and $b^{*}$ of samples at the range of 43.28-47.64, 11.57-14.00 and 20.52-26.46, respectively.

The changes in the chromatic coordinate $L^{*}$ after $96 \mathrm{~h}$ and $312 \mathrm{~h}$ of exposure are shown in Fig. 1a. The $\Delta L^{*}$ value of all samples decreased after $96 \mathrm{~h}$ of exposure. With the exposure continued to $312 \mathrm{~h}$, a further decrease in $\Delta L^{*}$ of sample A-C was observed, but the $\Delta L^{*}$ value of sample D exhibited a slight increase. Further, the $\Delta L^{*}$ values of samples A and B after $312 \mathrm{~h}$ exposure were obviously larger than that of samples $C$ and $D$, indicating that the addition of BTZ-1 was effective in enhancing the stability of the $L^{*}$ value upon UV irradiation.
The changes in the $a^{*}$ parameter of samples are illustrated in Fig. 1b. After $96 \mathrm{~h}$ of exposure, the smallest $\Delta a$ was observed for sample D, sample A presented the largest $\Delta a^{*}$, and all the samples showed changes in $a^{*}$ towards red. After $312 \mathrm{~h}$ of exposure, the $\Delta a^{*}$ values of samples $\mathrm{A}$ and $\mathrm{B}$ increased continuously, a greening tendency was observed for samples $C$ and $D$.

The changes in $b^{*}$ of samples with and without paints (Fig. 1c) show an opposite result after accelerated weathering. Sample A without coating has presented a pronounced yellowing tendency after $96 \mathrm{~h}$ and $312 \mathrm{~h}$ of exposure. However, a bluing effect was observed for samples B, C, and D after weathering. A similar result was observed by Cristea et al. [3].

The $\Delta E^{*}$ value represents the overall difference in the colour modulus or the colour stability. The $\Delta E^{*}$ values of the samples are compared in Fig. 1d. After $312 \mathrm{~h}$ of artificial accelerated weathering, the largest value of $\Delta E^{*}$ was obtained for sample A (5.87), which exhibited the highest susceptibility to UV radiation. Meanwhile, sample D presented the smallest value of $\Delta E^{*}$ (1.88), followed by sample $C$ (2.70). This illustrates that the application of the organic UV absorber coating was effective in improving the colour stability of bamboo scrimber upon exposure to UV radiation. The colour stability of sample D was 3.12 times that of sample A and 1.91 times that of sample B.

\section{Glossiness changes}

Figure 2 shows the $\Delta G \%$ of samples at $60^{\circ}$ angle of incidence after weathering. $\Delta G \%$ is defined as the percentage of the glossiness change of the sample during weathering relative to its initial glossiness value. As show in Fig. 2, $\Delta G \%$ decreases for all specimens. The glossiness changes are correlated with the degradation level of the surface coating during accelerated weathering. The UV radiation, moisture, oxygen, and other environment factors can cause the surface degradation of coatings and bamboo. The condensation of water induced the washing out of the degradation products on the material surface and consequently the underlying fresh surface was further exposed [3]. This process is bound to affect the surface smoothness, further affect light reflection, and reduce glossiness. The application of coating could improve the 

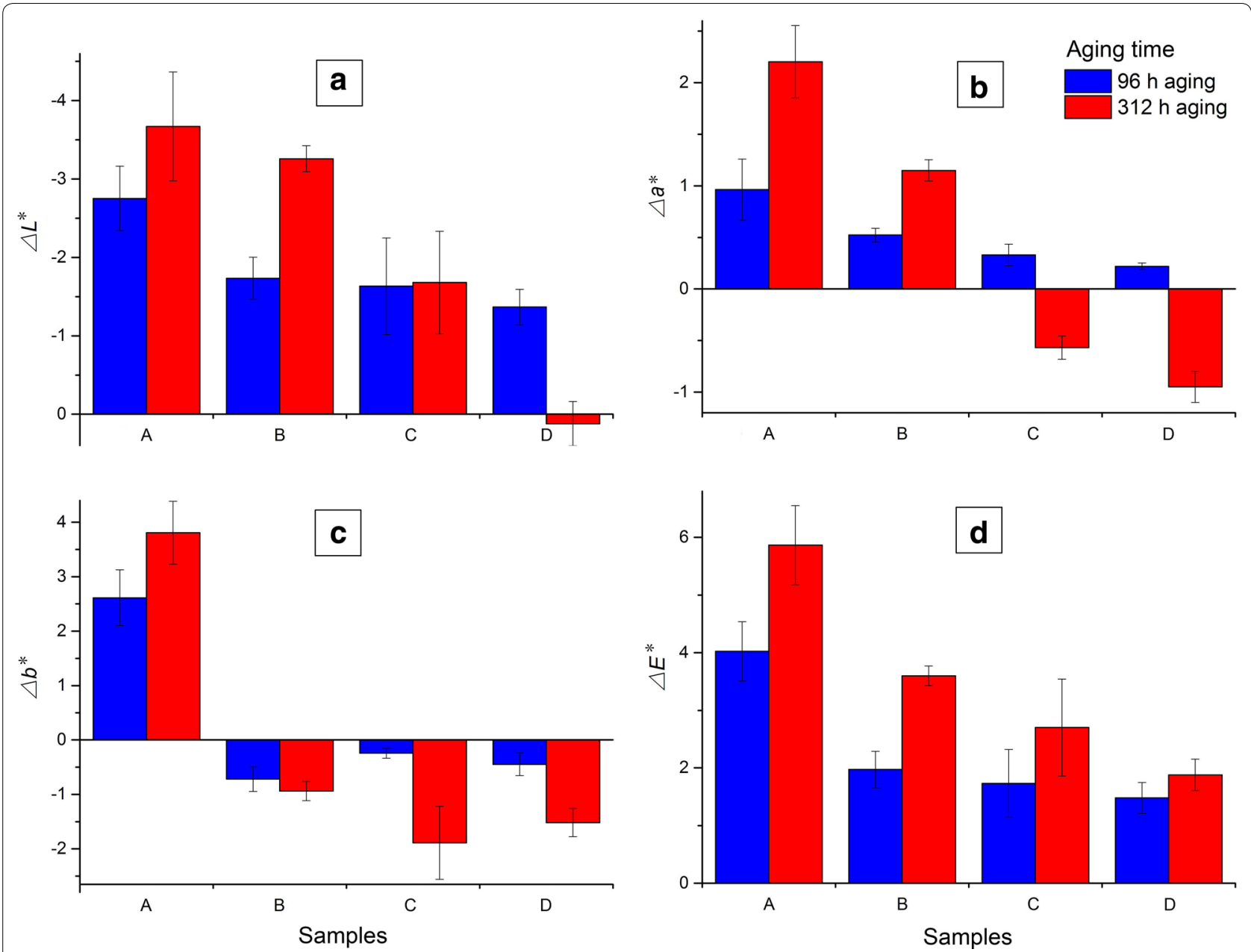

Fig. 1 Changes in $L^{*}(\mathbf{a}), a^{*}(\mathbf{b}), b^{*}(\mathbf{c})$, and $\Delta E^{*}(\mathbf{d})$ of samples during aging

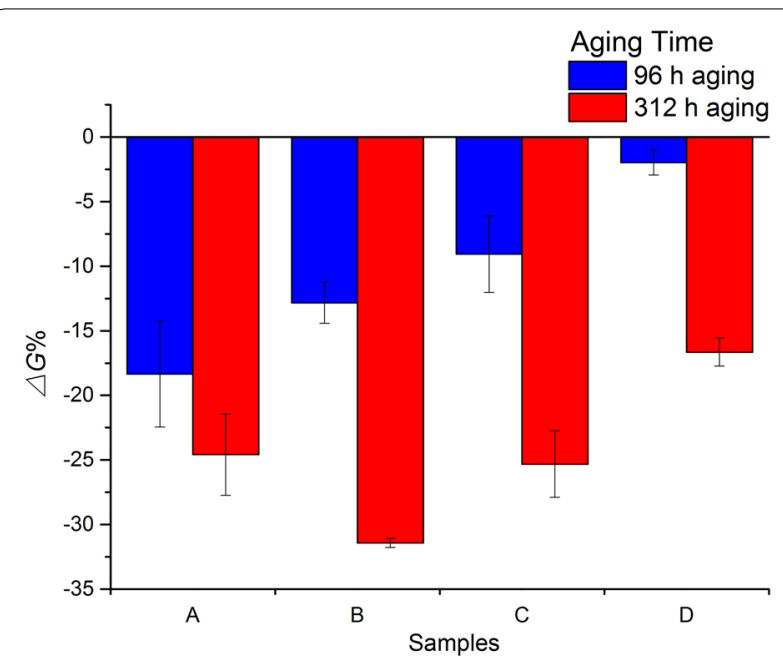

Fig. $2 \Delta G \%$ of samples during aging surface gloss of material. The glossiness of OBS increased to $10-22$ from only $0.6-0.8$ after painting. The $\Delta G \%$ value of sample A after $312 \mathrm{~h}$ of exposure was 24.6, while higher values were obtained for sample B (31.4). The smallest value of $\Delta G \%$ was observed for sample D (16.6), which was only $52.9 \%$ of the $\Delta G \%$ value of sample B. Thus, the results indicate that the organic UV absorber coating can increase the gloss stability of OBS.

\section{Wettability}

The wettability of samples before and after $312 \mathrm{~h}$ accelerated weathering was investigated by performing CA measurements and SFE calculations. Figure 3 shows the plot of CA evolution with the duration for which water was present on the surface of samples. The initial CAs of samples were obtained at the moment when the machine could detect the CA after the testing droplets touched the surface. The water CAs for samples with coatings and those without weathering exhibited small 


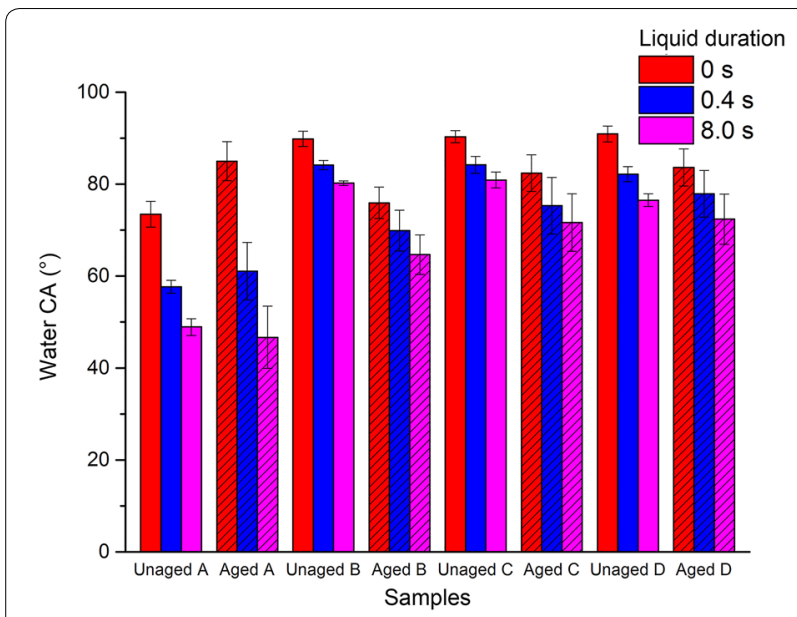

Fig. 3 Water CAs of samples before and after artificial aging

differences in the initial CAs and they were approximately $89.85^{\circ}-90.93^{\circ}$, and these values were obviously greater than those of the unaged sample A $\left(73.46^{\circ}\right)$, which shows that painting is effective in improving the hydrophobicity of the material surface. The initial water CA of sample A shows a noticeable increase after accelerated weathering, of approximately $13.86 \%$. However, the initial water CAs of sample B, C, and D exhibited a downward trend after accelerated weathering. The opposite trends of samples A and B-D are probably due to the different surface materials. The surface material of sample A is bamboo that consists of cellulose, hemicellulose, and lignin, the photooxidation of the $-\mathrm{OH}$ (hydrophile group) on the surface of sample A may increase the surface hydrophobicity. On the other hand, the surface material of samples B-D is the coating main component, namely, the resin, so the photodegradation of the hydrophobic surface of samples B-D may be the major reason which results in a decrease in the water $\mathrm{CA}$. The water $\mathrm{CA}$ of aged sample A shows a sharp deterioration after the water droplet stayed for $8 \mathrm{~s}$ on the sample surface, the rate of descent of aged sample A was greater than unaged sample A; a similar result was observed by Rao et al. [1]. This may be due to the photodegradation of lignin [25] which leads to capillary increase of material surface; the capillary action causes the water droplet to be absorbed quickly. Further, one can also be observed that sample D shows the smallest change in the initial water $\mathrm{CA}$, followed by sample $C$, which could be clearly observed in Fig. 4 . This reveals that the coating of organic UV absorber is effective in enhancing the water CA stabilities of OBS upon sunlight exposure. Further, it also illustrates that the application of the organic UV absorber reduces the weathering rate of the material surface.

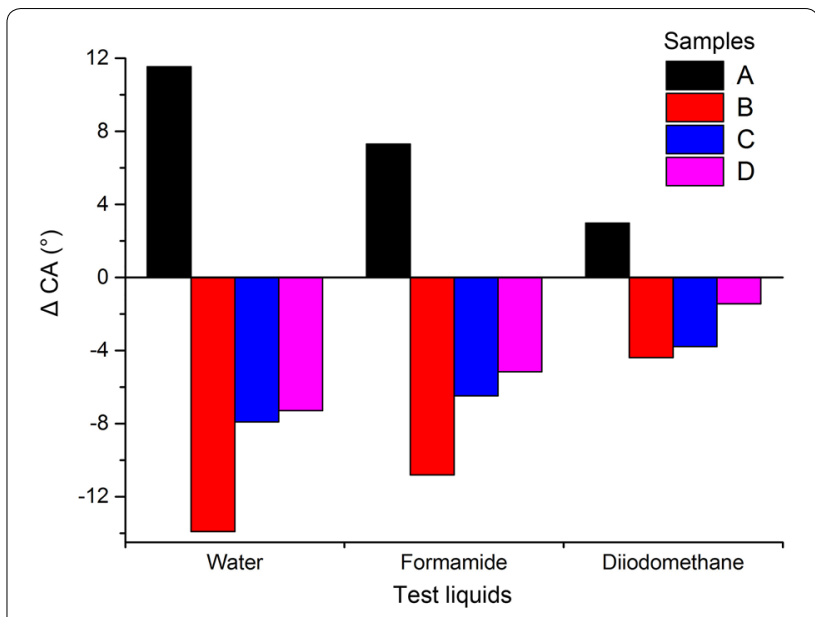

Fig. 4 Initial CA changes of samples before and after aging

The formamide CAs of samples before and after accelerated weathering are shown in Fig. 5. Both formamide and water are polar liquids. Similar results were obtained for formamide and water CAs; the initial formamide CAs of sample A rose markedly, while the rate of their decrease after weathering with time was larger than that of sample A without weathering. The initial formamide CAs of sample B, C, and D decreased after photodegradation. As shown in Fig. 4, the smallest change in the initial formamide CA after accelerated weathering is obtained for sample D: the value was only $47.74 \%$ of sample B's value. This confirms that the application of the organic UV absorber is effective in enhancing the CA stabilities of OBS upon exposure to UV light. The initial formamide CA change of sample $C$ was less than that of samples $A$ and $B$, but was bigger than that of sample $D$. This illustrates the good OBS protection effect as a result of appropriate application of an organic UV absorber.

Figure 6 illustrates the variation of diiodomethane CAs of samples before and after accelerated weathering with time. The diiodomethane CA of sample A without exposure to UV radiation was 67.42 , which is much bigger than that of samples B-D (55.39-57.55). This may be attributed to the application of organic paintings, which result in the increase in the samples' surface lipophilicity. Sample D shows the smallest change in the initial diiodomethane CA after weathering, followed by sample C. The results were similar to the water and formamide CAs. This reconfirms again that the application of the organic UV absorber in the UV-curable paint effectively protects $\mathrm{OBS}$ from photodegradation.

The SFE is a reflection of the surface molecular interatomic forces and is closely related to the solid surface wettability [22]. The SFE $\left(\gamma_{S}\right)$ and its components $\left(\gamma_{S}^{\mathrm{LW}}\right.$, $\gamma_{\mathrm{S}}^{\mathrm{AB}}, \gamma_{\mathrm{S}}^{+}$, and $\gamma_{\mathrm{S}}^{-}$) of samples calculated on the basis of the 


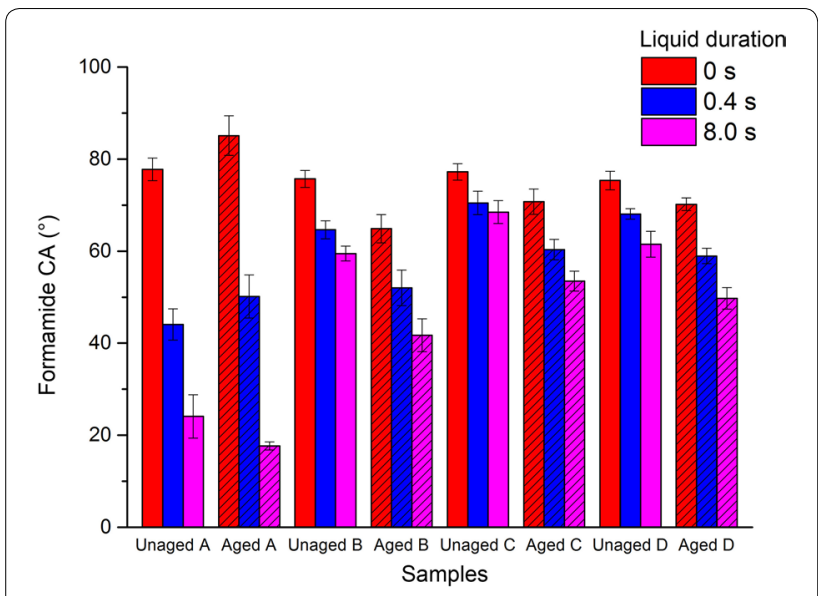

Fig. 5 Formamide CAs of samples before and after aging

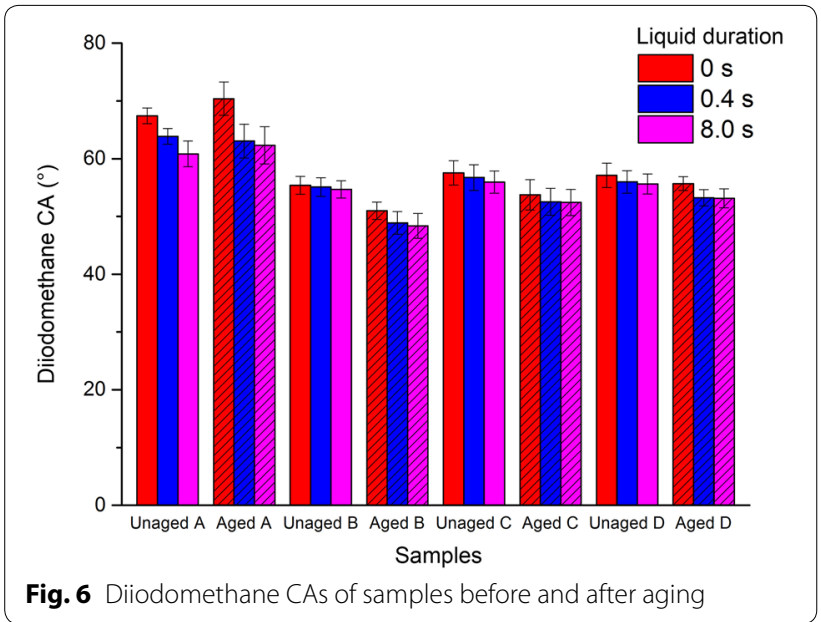

initial CAs are presented in Table 4. The changes in the samples' SFE after weathering are exhibited in Fig. 7. It can be clearly observed that the SFE of OBS significantly increased after coating. The SFE of sample A decreased after UV radiation exposure by $1.51 \mathrm{~mJ} \mathrm{~m}^{-2}$. This suggests that the weathering is disadvantage for OBS coating and painting. Meanwhile, the SFE of samples B-D showed a downward trend after $312 \mathrm{~h}$ weathering. The biggest change in SFE $\left(3.78 \mathrm{~mJ} \mathrm{~m}^{-2}\right)$ during weathering was observed in sample B, followed by sample C. Sample $\mathrm{D}$ showed the smallest change in SFE $\left(1.42 \mathrm{~mJ} \mathrm{~m}^{-2}\right)$ after $312 \mathrm{~h}$ of accelerated weathering. These results are similar to the results for colour, glossiness, and CAs. A conclusion can be deduced that coat d with BTZ-1 effectively promoted the SFE stability of the surface coatings.

\section{Interpretation ATR FT-IR spectra}

To further investigate the chemical change in the coating after weathering, the changes in the chemical functional groups of samples B and D were investigated by ATR FT-IR (Fig. 8). The test method (ATR FT-IR) does not damage material surface, so the results were not affected by the ground coating. In Fig. 8, the absorption peak intensities of sample D at $1731 \mathrm{~cm}^{-1}$ and $1242-1248 \mathrm{~cm}^{-1}$ (corresponding to the carbonyl group $(\mathrm{C}=\mathrm{O})$ stretching vibration and $\mathrm{C}-\mathrm{O}$ stretching vibration in acetic acid ester) were obviously lower than those of sample B. This result suggests that the adding of BTZ-1 in the coating may induce the decomposition of ester group. A similar result was observed at $1053-1062 \mathrm{~cm}^{-1}$, which is attributed to $\mathrm{C}-\mathrm{O}$ stretching vibration in primary alcohol. The absorption peak at $1731 \mathrm{~cm}^{-1}$ showed an increase in intensity after weathering. This implies that the coatings underwent a photo-oxidation reaction during UV radiation exposure. It also can be observed that the extent of increase in the absorption peak intensity at $1731 \mathrm{~cm}^{-1}$ of sample B was significantly higher than that of sample D. This result reveals the coating d protected itself from photooxidation upon UV light exposure. The great change in chromophoric group (for example: $\mathrm{C}=\mathrm{O}$ ) of sample $\mathrm{B}$ maybe result in great chromatism. The absorption

Table 4 Surface energies and the Lifshitz-van der Waals $\left(\gamma_{L}^{\mathrm{LW}}\right)$, Lewis acid-base $\left(\gamma_{s}^{\mathrm{AB}}\right)$, electron acceptor $\left(\gamma_{\mathrm{L}}^{+}\right)$, and electron donor $\left(\gamma_{L}^{-}\right)$components of samples

\begin{tabular}{llllll}
\hline Samples & $\boldsymbol{\gamma}_{\mathbf{S}}\left(\mathbf{m}_{\mathbf{J}} \mathbf{m}^{2}\right)$ & $\boldsymbol{\gamma}_{\mathbf{S}}^{\mathbf{L W}}\left(\mathbf{m}_{\mathbf{J}} \mathbf{m}^{2}\right)$ & $\boldsymbol{\gamma}_{\mathbf{S}}^{\mathbf{A B}}\left(\mathbf{m}_{\mathbf{J}} \mathbf{m}^{2}\right)$ & $\boldsymbol{\gamma}_{\mathbf{S}}^{+}\left(\mathbf{m J ~ m}^{2}\right)$ & $\boldsymbol{\gamma}_{\mathbf{S}}^{-}\left(\mathbf{m}^{\mathbf{J}} \mathbf{m}^{\mathbf{2}}\right)$ \\
\hline Unaged A & 18.12 & 24.33 & -6.21 & 0.34 & 27.95 \\
Unaged B & 29.31 & 31.22 & -1.91 & 0.15 & 6.00 \\
Unaged C & 27.89 & 29.99 & -2.10 & 0.17 & 6.36 \\
Unaged D & 29.25 & 30.23 & -0.99 & 0.05 & 4.97 \\
Aged A & 16.61 & 22.65 & -6.04 & 0.53 & 17.33 \\
Aged B & 33.09 & 33.71 & -0.63 & 0.007 & 13.51 \\
Aged C & 30.45 & 32.16 & -1.70 & 0.07 & 10.15 \\
Aged D & 30.67 & 31.05 & -0.38 & 0.004 & 8.52 \\
\hline
\end{tabular}




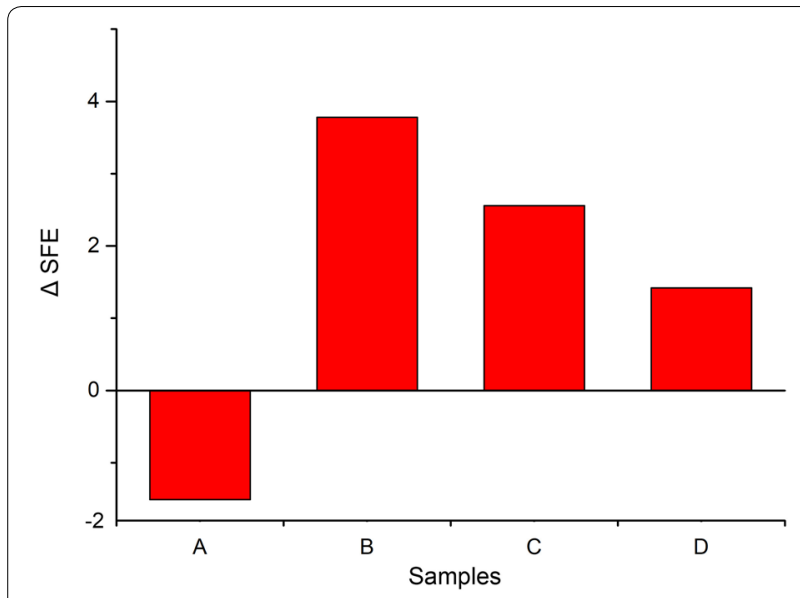

Fig. 7 SFE changes of samples after aging

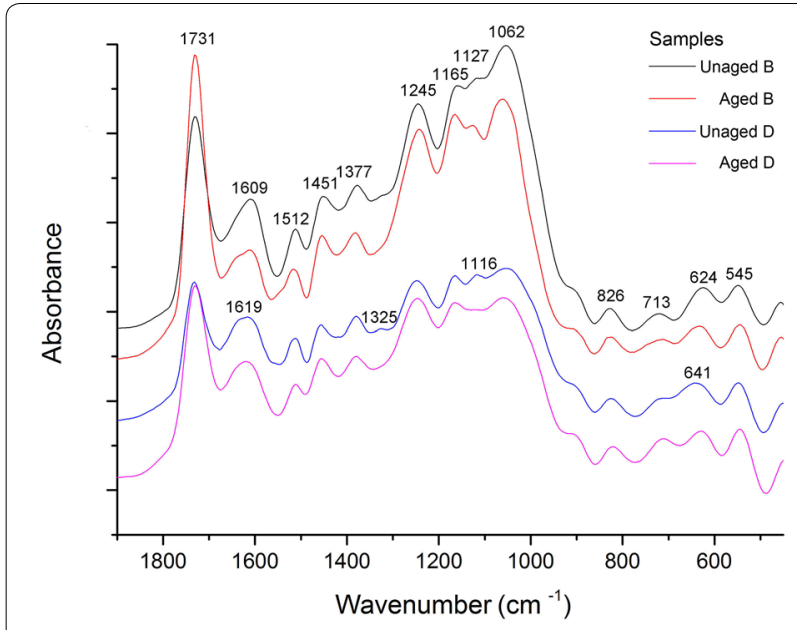

Fig. 8 ATR-FTIR spectra of samples $B$ and $D$ before and after aging

peak at $1609-1619 \mathrm{~cm}^{-1}$ of sample $\mathrm{B}$, attributed to the benzene ring structure, showed a slight decrease; however, the change in this peak of sample $\mathrm{D}$ was difficult to detect. The stability at $1609-1619 \mathrm{~cm}^{-1}$ of sample $\mathrm{D}$ is characteristic of good performance and the antiphotodegradation capability of the coating $\mathrm{d}$. The peak at $1116-1127 \mathrm{~cm}^{-1}$ of sample D almost disappeared after violent radiation. It maybe due to the unstable of $\mathrm{C}-\mathrm{O}$ vibration in alkyl ether with side chain under the influence of temperature result of the transformation of UV light to heat by UV absorber. Overall, the ATRFTIR spectra demonstrate the effectiveness of the UV absorber (BTZ-1) in reducing the photodegradation of coatings.

\section{Conclusions}

The photodegradation of biological materials is a great challenge to overcome for outdoor application of biomass products. In this study, an organic UV absorber coating that consist of a UV-curing paint, ethyl acetate, anhydrous alcohol, and BTZ-1 was prepared, and the behaviour of this coating applied on OBS (sample D) when exposed to UV radiation was investigated. The colour characterization has demonstrated the efficiency of the organic UV absorber coating in promoting the stability of $L^{\prime \prime}$ and $\Delta E^{*}$. The results of glossiness showed that the organic UV absorber coating exhibited a high gloss retention during weathering treatment. A positive correlation between CAs and SFE stabilities of samples and the application amount of the organic UV absorber (BTZ-1) was noticed. The chemical structure of the coating after the addition of the organic UV absorber became more stable during exposure. The slight colour change, high gloss retention, slight CAs/SFE changes, and high functional group stability illustrate that the rate of degradation is much lower for sample $\mathrm{D}$ with the applied coat $\mathrm{d}$ than that for the control sample (A and B). In conclusion, the addition of the organic UV absorber improved the exterior durability of OBS. The coating $d$ is considered to be the best UV shielding layer in this study and is effective in protecting OBS and reducing the surface photodegradation of the substrate and the coating.

\section{Authors' contributions}

$\mathrm{NL}$ participated in whole experiments and writing works. YC and YB designed this study. MB analyzed FTIR and surface free energy data. FR, YS, CH and ZH completed part of the experimental work. RG and CX provided some contributor writing the manuscript. All authors read and approved the final manuscript.

\section{Author details}

${ }^{1}$ China National Bamboo Research Center, Hangzhou 310012, People's Republic of China. ${ }^{2}$ Research Institute of Wood Industry, Chinese Academy of Forestry, Beijing 100000, People's Republic of China. ${ }^{3}$ Key Laboratory of High Efficient Processing of Bamboo of Zhejiang Province, Hangzhou 310012. People's Republic of China. ${ }^{4}$ Sichuan Academy of Forestry, West Xinghui Road 18, Chengdu 610081, People's Republic of China.

\section{Acknowledgements}

This work was financial supported by the Fundamental Research Funds for the Central Non-profit Research Institution of CAF (CAFYBB2018MB008; CAFYBB2017ZX 003).

\section{Competing interests}

The authors declare that they have no competing interests.

\section{Availability of data and materials}

The datasets used and/or analysed during the current study are available from the corresponding author on reasonable request.

\section{Consent for publication}

All authors approve of the publication on your journal if this paper has been received.

Ethics approval and consent to participate

All authors approve of its submission to Journal of Wood Science. 


\section{Funding}

This work was financial supported by the Fundamental Research Funds for the Central Non-profit Research Institution of CAF (CAFYBB2018MB008; CAFYBB2017ZX 003).

\section{Publisher's Note}

Springer Nature remains neutral with regard to jurisdictional claims in published maps and institutional affiliations.

Received: 17 October 2018 Accepted: 6 February 2019

Published online: 20 February 2019

\section{References}

1. Rao F, Chen Y, Li N, Zhao X, Bao Y, Wu Z, Ren D, Xu J, Cai H (2017) Preparation and characterization of outdoor bamboo-fiber-reinforced composites with different densities. BioResources 12:6789-6811

2. Sombatsompop N, Chaochanchaikul K, Rosarpitak V (2013) Photodegradation profiles of pvc compound and wood/pvc composites under UV weathering. Express Polym Lett 7:146-160

3. Cristea MV, Riedl B, Blanchet P (2010) Enhancing the performance of exterior waterborne coatings for wood by inorganic nanosized UV absorbers. Prog Org Coat 69:432-441

4. George B, Suttie E, Merlin A, Deglise X (2005) Photodegradation and photostabilisation of wood - the state of the art. Polym Degrad Stab 88:268-274

5. Li N, Chen Y, Bao Y, Zhang Z, Wu Z, Chen Z (2015) Evaluation of UVpermeability and photo-oxidisability of organic ultraviolet radiationabsorbing coatings. Appl Surf Sci 332:186-191

6. Almagro M, Maestre FT, Martínez-López J, Valencia E, Rey A (2015) Climate change may reduce litter decomposition while enhancing the contribution of photodegradation in dry perennial Mediterranean grasslands. Soil Biol Biochem 90:214-223

7. Zhu J, Yang D, Geng J, Chen D, Jiang Z (2008) Synthesis and characterization of bamboo-like Cds/Tio nanotubes composites with enhanced visible-light photocatalytic activity. J Nanopart Res 10:729-736

8. Yu Y, Jiang Z, Wang G, Tian G, Wang H, Song Y (2012) Surface func tionalization of bamboo with nanostructured ZnO. Wood Sci Technol 46:781-790

9. Lowry MS, Hubble DR, Wressell AL, Vratsanos MS, Pepe FR, Hegedus CR (2008) Assessment of UV-permeability in nano-ZnO filled coatings via high throughput experimentation. J Coat Technol Res 5:233-239

10. Liufu SC, Xiao HN, Li YP (2005) Thermal analysis and degradation mechanism of polyacrylate/ZnO nanocomposites. Polym Degrad Stab 87:103-110
11. Farrokhpay S (2009) A review of polymeric dispersant stabilisation of titania pigment. Adv Colloid Interface Sci 151:24-32

12. Hong RY, Li JH, Chen LL, Liu DQ, Li HZ, Zheng Y, Ding J (2009) Synthesis, surface modification and photocatalytic property of $\mathrm{ZnO}$ nanoparticles. Powder Technol 189:426-432

13. Mahmoudifard M, Safi M (2012) Novel study of carbon nanotubes as UV absorbers for the modification of cotton fabric. J Text Inst 103:893-899

14. Rajan W, Wäber R, Wieser J (2012) Influence of different types of UV absorber/UV stabilizer combination on the photodegradation of pc/abs blend. J Appl Polym Sci 124:4007-4015

15. Liu Z, Chen S, Zhang J (2013) Effect of UV absorbers and hindered amine light stabilizers on the photodegradation of ethylene-octene copolymer. J Appl Polym Sci 127:1135-1147

16. Forsthuber B, Schaller C, Grüll G (2013) Evaluation of the photo stabilising efficiency of clear coatings comprising organic UV absorbers and mineral UV screeners on wood surfaces. Wood Sci Technol 47:281-297

17. Forsthuber B, Müller U, Teischinger A, Grüll G (2013) Chemical and mechanical changes during photooxidation of an acrylic clear wood coat and its prevention using UV absorber and micronized $\mathrm{TiO}_{2}$. Polym Degrad Stab 98:1329-1338

18. ASTM G154-12a (2014) Standard practice for operating fluorescent ultraviolet (UV) lamp apparatus for exposure of nonmetallic materials. ASTM International, West Conshohocken

19. ASTM E1347-06 (2007) Standard test method for color and colordifference measurement by tristimulus. ASTM International, West Conshohocken

20. ASTM D523 (2014) Standard test method for specular gloss. ASTM International, West Conshohocken

21. Fombuena V, Balart J, Boronat T, Sánchez-Nácher L, Garcia-Sanoguera D (2013) Improving mechanical performance of thermoplastic adhesion joints by atmospheric plasma. Mater Des 47:49-56

22. Li N, Bao M, Chen Y, Zhang Y, Bao Y, Yu W (2017) Influence of density on properties of compressed weeping willow (Salix babylonica) wood panels. Forest Prod J 67:44-49

23. Van Oss CJ, Chaudhury MK, Good RJ (1988) Interfacial Lifshitz-van der Waals and polar interactions in macroscopic systems. Chem Rev 88:927-941

24. Bryne LE, Wålinder MEP (2010) Ageing of modified wood. Part 1: wetting properties of acetylated, furfurylated, and thermally modified wood. Holzforschung 64:295-304

25. Li N, Chen Y, Yu H, Xiong F, Yu W, Bao M, Wu Z, Huang C, Rao F, Li J, Bao Y (2017) Evaluation of optical properties and chemical structure changes in enzymatic hydrolysis lignin during heat treatment. RSC Adv 7:20760-20765

\section{Submit your manuscript to a SpringerOpen ${ }^{\odot}$ journal and benefit from:}

- Convenient online submission

- Rigorous peer review

- Open access: articles freely available online

- High visibility within the field

- Retaining the copyright to your article

Submit your next manuscript at springeropen.com 